\title{
Preliminary Study on Cultivation of Architectural Design Ability in Classroom Teaching
}

\author{
Fangxin OUYANG \\ School of civil engineering and architecture, Wuhan polytechnic university, Wuhan, 430023 China
}

\begin{abstract}
Ability develop is important goal in classroom teaching and architectural design ability is the essential part of ability for architecture students. Therefore, how to develop architectural design ability is the important issue we must discuss in teaching practice. In this paper, we have presented some teaching tactics for development of architectural design ability.
\end{abstract}

KEYWORD: ability develop; teaching means; basic training

\section{INTRODUCTION}

Architecture design is the important curriculum of architecture student, it is consist of several parts such as architectural design basic, the first step of architecture and architectural design 1-6, and students would spend four years to learning these contents. After learning this course, people would master some professional knowledge including basic concepts and rules of architectural design which are necessary knowledge for further learning. At the same time, they should get professional ability of architectural design[1].

Before learning architectural design course, students have little drafting abilities such as drawing plan, façade, profile and perspective view, but their design ability is weak. By classroom teaching, student should master the architectural design processes which include overall understanding and analysis of design requirement, creation of spatial body meeting use function and in keeping with some aesthetic principles, and accomplishing design drawing using exact engineering language at last [2],[3]. Obviously, it is difficult to develop the ability rapidly. In teaching practice, students often feel helpless when they face to some architectural design projects. We must change this situation and develop students' abilities of analysis and solving problems. There are many ways to reach the target, but we mainly discuss the classroom teaching in this paper.

\section{COMPONENTS OF ARCHTITECTURAL DESIGN ABILITY}

\subsection{Emphasizing the importance of basic training}

All specialty teaching must begin from basic, so architectural design teaching must begin from acquainting with architecture. It is important to grasp basic theory to achieve architectural design ability. To develop this ability, student should get many sorts of basic knowledge such as understanding architectural characteristic, design performance techniques, history of architecture and architectural aesthetics, and do some skill training such as constructing blueprint and drawing. The integral expressiveness training would make student develop design expression ability.

The essence of architecture is space. Student should have the ability that they could compose some spatial concepts from basic line express, and convey the idea of designer using signal factors. At last, student would combine the architectural physical, space and color together to complete architectural design. This is the other design ability coming from basic training.

\subsection{Developing innovation ability}

In the stage of basic knowledge and skill, concepts, training and practice are paid more attentions. In the advanced stage, culturing modern design idea and method are more important to student. Therefore, exploiting their innovative design ability should be the main goal, and classroom teaching should carry out some training mainly for innovation.

At first, we should analyze the building modeling and decompose the integral building into some basic 
units and elements which would be abstracted into some spatial elements such as point, line and area. And then, after taking into account some rules such as relations between global and local, or micro and micro, these basic units would be design. In this process, student would realize that building in design can be broken up from the whole into parts, and be composed according to the creative. Through these trainings, the thinking of students would be animated, and all of their judgment ability, spatial perception ability and innovation ability would be enhanced. In fact, these are the method and principle of modern building modeling design.

\subsection{Developing ability of three-dimensional and spatial modeling}

After learning to express building by point, line and area, students must develop ability of threedimensional and spatial modeling which is indispensable in building design. In practice, we use teaching models to train students' design ability of spatial concept, by which they could understand intuitively from some aspects such as body type, position and structure of building. Furthermore, we encourage student to make building model according to design drawings, express design works in threedimensional space. By this way, student could develop strong ability of three-dimensional and spatial modeling, and they would be interested in this teaching method too. Therefore, they would enter building design field rapidly and ease.

\subsection{Developing ability of contacting theory with practice}

Whichever studying course, we must emphasize contacting theory with practice. We would develop ability to solve practical problems which is guided by theory. How could we contact theory with practice in practical architectural design? We think that we should take a big step and break the some constraints, obtain the ability through practice. For example, we have ever asked student to make architectural design about alteration project of their academic building and some other projects. In these works, design conditions are chosen by students themselves, which could make them do the distinctive designs on the basis of their understandings and ideas. This type of tasks could lead student to find out the demands of sociality and business owners better, and know well more design conditions. Furthermore, they could arouse students' creation enthusiasm greatly, improve their ability of contacting theory with practice, and form the concept firmly that truth must be submitted practice.

\section{RELATIONSHIP BETWEEN DEVELOPMENT ABILITY AND TEACHING METHOD}

As we know, it is mainly by classroom teaching that student obtain professional knowledge and develop ability in school education. In teaching practice, we have done some works to study the course, student and relationship between both of them. From this, we have found out some rules about design course and some experiences as follows.

\subsection{Insisting on heuristic teaching method}

Nowadays, students have sharp and active thinking, and they require more efficient teaching method. If we attend class with poor teaching method, the effect would be not good. Therefore, we have use heuristic teaching method to attend class. The process has five steps as follow. At first, according to teaching objectives, some questions have been asked. Secondly, teacher point the emphasis of these questions which could urge student to think actively. Thirdly, students answer the questions. The last two steps are students' evaluation and teacher's commenting. The process figure is as follow. (See Fig.1)

We give an example for explaining the teaching process. (See Fig.2)

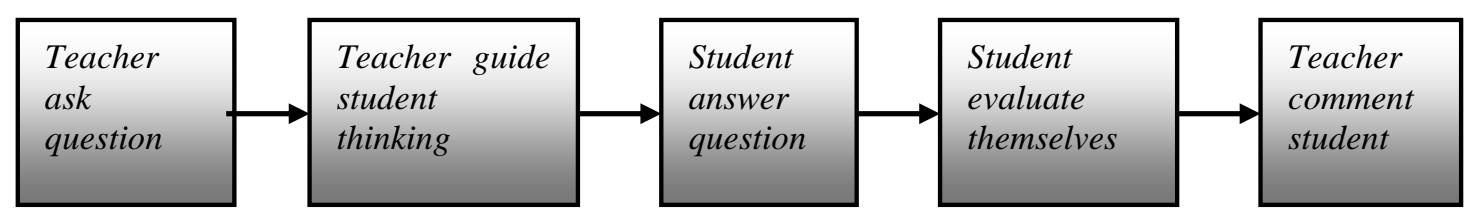

Figure1. Flow diagram of heuristic teaching method

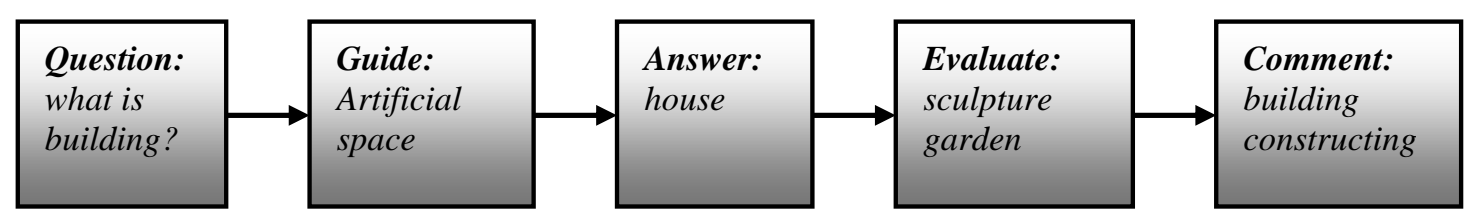

Figure2. Example of heuristic teaching method 


\subsection{Conversation method}

Conversation method is a traditional teaching method, it is used widely. Usually, teacher ask student some coherent and heuristic questions which come from the teaching objectives, and student answer these questions correctly after thinking seriously. In the process of thinking and answering, student could obtain new knowledge and develop new skill.

When using this method, we should pay attention to the quality of question. At first, the level of question should be suitable for student and heuristic, the statements should be clear and easy to understand, and all questions should be related logically. Secondly, when asking question, we should aim to all students, but not to one or two. Thirdly, in teaching process, teacher would ask student some questions and students could ask teacher some questions too.

Teacher should make teaching plan in detail, prepare a lesson carefully and write down the conversation outline. The questions should be answered by different level students. Furthermore, teacher should listen to the students carefully, no matter the answer is correct or wrong, they must have clear attitude.

\subsection{Associated method}

When making architectural design, we would use different types of knowledge. Therefore, when teachers give lesson, they should make students clear that old and new knowledge is related, and the new would be learned by restudying the old. In architectural design, we use project drawing to express design idea, so it is the working language of design which must be grasped by all of us. Some building components can be represented by architectural symbols. For example, we could use a point to denote a pillar and a line to denote a wall. By connecting in the mind, student could compare building components in the real world with architectural symbols, and they would understand the meaning of working drawing better.

\subsection{Game teaching method}

The game teaching method is that students learn by means of playing game. With this method, students could learn the knowledge in textbook and grasp skills in teaching goal in lively atmosphere, enjoyable activities and fierce competition. The method is liked by students and has very good effects in practice. In our classroom teaching, we ask student to do architectural design by themselves, everyone has different program though the task is same. When showing the final works in class, we use the game teaching method which would make students develop ability fully and shorten the distance between teacher and students. In particular, students would be divided into certain number of groups, and every group should do distinctive work. At last, we apply the means of competition to evaluate their works. By showing courseware, these groups would gain different score, and they would be assessed to different level. The winners would get corresponding encourage and reward.

\subsection{Metaphor teaching method}

In teaching, intuition and abstract as if visualization and reality are different aspects we must face. To some too abstractive knowledge, we should use metaphor method to explain it by taking intuitive examples or examples which students know well. In addition, we could lead them to look some issues from another point of view, and understand profound concept by vertical and horizontal comparison. For example, when learning the concept of flow space in architecture, students have not understood it. In order to do this, we use metaphor method to explain that flow is you have me and me have you.

\section{CONCLUSION}

Classroom teaching and ability development are inseparable, correct teaching method could improve teaching efficiency greatly. In this paper, we discuss the ways for development of architectural design ability, and think that architectural design ability embodies four aspects such as basic theory, innovation ability, spatial modeling ability and ability of contacting theory with practice. Furthermore, we discuss the teaching methods for improving ability which are heuristic teaching method, conversation method, associated method, game teaching method and metaphor teaching method. The application of these methods could develop students' architectural design ability better.

\section{REFERENCES}

[1] Shao Yu and Zou Guangtian, Foreign education for architectural design innovation and its enlightenment, Architectural Journal, 2008, 10

[2] Wang Yuan and Ye Minghui, "From point to area": research for teaching methods of foreign architectural history, Huazhong Architecture, 2011, 4

[3] Andy Hargreaves, Teaching in the knowledge society, shanghai, East China Normal University press, in Chinese, 2007 